\title{
MicroRNA-126: A new and promising player in lung cancer (Review)
}

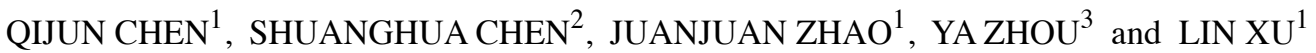 \\ ${ }^{1}$ Department of Immunology, Special Key Laboratory of Gene Detection and Therapy of Guizhou Province, \\ Zunyi Medical University; ${ }^{2}$ Department of General Medicine, The Third Hospital Affiliated to Zunyi Medical University; \\ ${ }^{3}$ Department of Medical Physics, Zunyi Medical University, Zunyi, Guizhou 563000, P.R. China
}

Received June 28, 2020; Accepted October 19, 2020

DOI: $10.3892 / \mathrm{ol} .2020 .12296$

\begin{abstract}
Lung cancer is one of the most common malignant tumors associated with cancer death; however, the mechanisms involved in lung tumor development have not been completely elucidated, which impedes the advancement of clinical diagnosis and therapy. MicroRNA-126 (miR-126) is an important member of the microRNA family and is encoded by intron 7 of epidermal growth factor-like domain-containing gene 7 . Increasing evidence has demonstrated that miR-126, as a distinct endothelial-enriched miRNA and new tumor suppressor gene, serves a promising role in the occurrence, development and metastasis of various types of cancer, including liver cancer, colorectal cancer, melanoma and lung cancer. In the present review, the current knowledge of the role of miR-126 in lung cancer growth, metastasis, diagnosis and prognosis as well as therapy was summarized, which may provide new insights on the biological roles of miRNAsin lung cancer and facilitate the
\end{abstract}

Correspondence to: Professor Lin Xu, Department of Immunology, Special Key Laboratory of Gene Detection and Therapy of Guizhou Province, Zunyi Medical University, 6 West Xuefu Road, Zunyi, Guizhou 563000, P.R. China

E-mail: xulinzhouya@163.com

Abbreviations: AKT, protein kinase B; AUC, area under the curve; CI, confidence interval; Crk, v-crk sarcoma virus CT10 oncogene homologue; EGFL7, epidermal growth factor-like domain-containing gene 7; EMT, epithelial-mesenchymal transition; ERK, extracellular protein kinase; HR, hazard ratio; lncRNA-PVT1-5, long non-coding RNA-PVT1-5; MAPK, MAP kinase; miRNAs, microRNAs; miR-126, microRNA-126/miRNA-126; MVD, microvessel density; NSCLC, non-small cell lung cancer; OS, overall survival; PFS, progression-free survival; PI3K, phosphatidylinositol-3 protein kinase; PTEN, phosphatase and tensin homologue; SLC7A5, solute carrier family 7 (cationic amino acid transporter, y+ system) member 5; TBMS1, tubeimoside-1; TFs, transcription factors; Tregs, regulatory $\mathrm{T}$ cells; VEGF-A, vascular endothelial growth factor A; VEGF, vascular endothelial growth factor; VEGFR-2, vascular endothelial growth factor receptor-2

Key words: lung cancer, microRNA-126, therapy, growth, metastasis ultimate development of miRNA-based therapies in clinical patients with non-small cell lung cancer.

\section{Contents}

1. Introduction

2. miR-126 and lung cancer tumorigenesis

3. miR-126 and lung cancer diagnosis

4. miR-126 and lung cancer prognosis

5. miR-126 as a potential target for lung cancer therapy

6. Conclusion

\section{Introduction}

Lung cancer is the leading cause of cancer mortality worldwide, and $>1$ million people die of this disease each year since 2006 (1). However, the complicated mechanisms involved in tumor development have not been completely elucidated, which impedes the development of early lung cancer diagnosis and therapy $(2,3)$. Hence, to develop effective clinical therapies against lung cancer, it is extremely urgent that the potential molecular mechanism of lung cancer development be further explored. Previous studies have discovered that a class of small non-coding RNAs, namely microRNAs (miRNAs), serve as intermediate regulators of cellular biological functions such as cell development, growth and apoptosis, which has opened up a whole field of genomics called microR Nomics $(4,5)$. Importantly, numerous studies have shown that miRNAs play critical roles in the development and metastasis of lung cancer, and miRNAs have emerged as potential factors in the early diagnosis and prognosis of lung cancer.

MicroRNA-126 (miRNA-126, miR-126) is an important member of the miRNA family, encoded by intron 7 of epidermal growth factor-like domain-containing gene 7 (EGFL7) on human chromosome 9q34.3 (6,7). Three EGFL7 isoforms (named EGFL7 isoform A, B and C), all of which contain the same open reading frame but are transcribed from separate promoters, utilize alternative exons (Fig. 1). At the transcriptional level, miR-126 may silence genes such as $m T O R, P I K 3 R 2$, and indirectly regulate EGFL7 isoform $B(8-10)$. Currently, miR-126 has been reported to have 
altered expression in various cancer tissues, including liver, colorectal cancer and melanoma as well as lung cancer, and it has been well studied for its role in lung cancer tumorigenesis as well as in diagnosis and therapy $(2,11-15)$, indicating the promising role of miR-126 in lung cancer treatment.

\section{2. miR-126 and lung cancer tumorigenesis}

miR-126 and cancer cell growth. Numerous studies have documented that miR-126 can control the growth of lung cancer cells. For instance, miR-126 can mediate the activation of the signal transducer and activator of transcription 3 signaling pathway to regulate the malignant biological behavior of non-small cell lung cancer (NSCLC) cells including their proliferation, migration, cell cycle entry and apoptosis susceptibility (16). In addition, miR-126 can activate the proapoptotic and antimetastatic effects in lung cancer cells by blocking the vascular endothelial growth factor A (VEGF-A)/vascular endothelial growth factor receptor-2 (VEGFR-2)/extracellular protein kinase (ERK) signaling pathway (17). Recently, Chen et al (18) demonstrated that silencing miR-126 could reverse the anticancer effects of naringin on NSCLC cell growth, in which naringin induces a reduction in the phosphatidylinositol-3 protein kinase (PI3K)/protein kinase B (AKT)/mechanistic target of rapamycin and suppresses vascular cell adhesion molecule 1 protein levels. In addition, miR-126 exhibits a suppressive effect on NSCLC cell invasion by interacting with three hub genes: VEGFA, AKT1, and Kirsten rat sarcoma viral oncogene homologue (19). Additionally, other studies have demonstrated that miR-126 can suppress the growth, migration and invasion of NSCLC cells by targeting chemokine (C-C motif) receptor 1 and solute carrier family 7 (cationic amino acid transporter, $\mathrm{y}+$ system) member 5 (SLC7A5) or v-crk sarcoma virus CT10 oncogene homologue (Crk) (20-23), indicating that miR-126 may control the growth of lung cancer cells through multiple targets (Table I).

miR-126 and cancer cell metastasis. It is universally acknowledged that epithelial-mesenchymal transition (EMT) serves a critical role in lung cancer metastasis (24-26). Studies have demonstrated that miR-126 is a key regulator that controls EMT signaling in lung cancer. For instance, in SPC-A1 lung cancer cells, ectopic expression of miR-126 significantly suppresses the EMT process by directly targeting PI3K/AKT/Snail signaling, which is considered to be the initial step of tumor metastasis (27). Consistently, the upregulation of miR-126 can also inhibit the migratory and invasive abilities of NSCLC cells by decreasing the expression of the target gene PIK3R2 and influencing the transduction of the phosphatase and tensin homologue (PTEN)/PI3K/AKT signaling pathway $(10,28)$. Further studies have demonstrated that both strands of the miR-126 and the complementary 'passenger strand' of the miR-126 duplex simultaneously target cytokine stromal cell-derived factor- $1 \alpha$ to reduce the recruitment of mesenchymal stem cells and inflammatory monocytes to primary tumors, thereby inhibiting lung metastasis (29). This indicates that miR-126 may regulate metastasis by affecting the tumor microenvironment (29). In addition, miR-126 has been identified in the miRNA-transcription factor (TF) target regulatory network in cancer metastasis (30). Novel differentially expressed genes including glutamate receptor, metabotropic 8 and dachshund family transcription factor 1 are all regulated by miR-126, which is implicated in the lymph node metastasis process of small cell lung cancer (30). However, the exact role of miR-126 in TF-miR networks, especially the interaction among these different TFs in lung cancer metastasis remains to be elucidated.

miR-126 and angiogenesis. Angiogenesis is well known as a representative event in tumorigenesis (31-34). miR-126 is generated from a subset of $E g f l 7$ transcripts in which intron 7 is retained (35). EGFL7 is a member of the epidermal growth factor-like protein family and is an extracellular matrix-associated protein expressed in activated endothelium $(36,37)$. Studies have reported that miR-126 and Egfl7 can regulate angiogenesis and maintain vascular integrity through both their interaction and their independent action (35,38-40). Notably, it has been revealed that EGFL7, insulin receptor substrate-1 and Crk are important miR-126 targets in lung cancer tumorigenesis. The aforementioned targets can inhibit tumor growth by modulating tumor angiogenesis $(40,41)$.

In addition, $V E G F-A$ serves an important role in the effect of miR-126 in cancer angiogenesis $(42,43)$. VEGF-A is an essential angiogenic growth factor that is a powerful promoter of the adhesion and proliferation of vascular endothelial cells $(44,45)$. Hence, VEGF-A can regulate the development of various cancers including liver cancer, colorectal cancer, melanoma and lung cancer (46-49). MiR-126 can inhibit the expression of sprouty-related EVH1 domain-containing gene 1 (SPRED), an inhibiting factor of the MAP kinase (MAPK) pathway, and the p3kr2 (PI3KR2/p85-b) gene, a subunit of PI3K (50-52). When miR-126 is downregulated, the overexpression of SPRED and the PI3K regulatory subunit suppresses the MAPK and PI3K signal pathways, which affects the transmission of VEGF-A and leads to further angiogenesis (50-52). Hence, investigating of miR-126 indicates that it may be used as a vascular endothelial cell-specific regulator of angiogenic signaling (35). Similarly, studies have revealed that angiogenesis may be promoted by the downregulation of miR-126 expression, which can lead to increased microvessel density (MVD) in lung cancer tissue $(53,54)$. In addition, MVD and the levels of vascular endothelial growth factor (VEGF) are both reduced dramatically once miR-126 expression is restored, which results in the inhibition of the growth of lung cancer (53).

\section{miR-126 and lung cancer diagnosis}

Recent studies have suggested that miR-126 may serve as an exciting new diagnostic biomarker of lung cancer (Table II). For example, Shang et al (55) demonstrated that the specificity and sensitivity of serum miR-126 levels in predicting NSCLC development were 84.3 and $96.40 \%$, respectively. In addition, Yang et al (56) demonstrated that the diagnostic performances of miRNAs such as miR-21, miR-223, miR-155 and miR-126 in serum and plasma in lung cancers were good and that serum miRNAs performed better compared with plasma miRNAs, with a sensitivity of $79 \%$, specificity of $78 \%$, positive likelihood ratio of 3.7, diagnostic odds ratio of 14 and area under the curve (AUC) of $85 \%$. Even the diagnostic accuracy of these miRNAs on stage I/II and an additional stage I group was similar to 


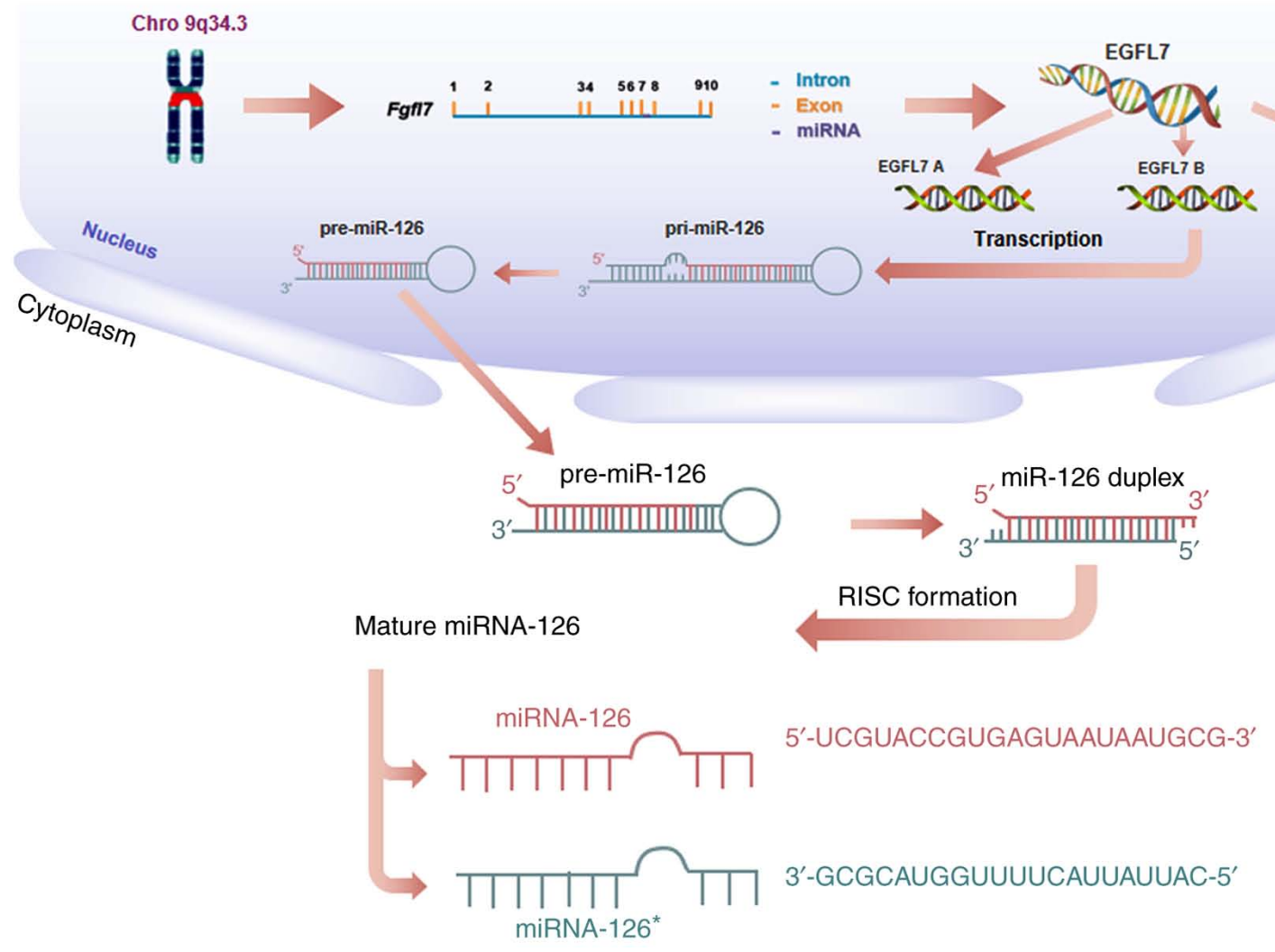

Figure 1. Biogenesis of miR-126. miR-126 is transcribed from the intron of the Fgfl7 genomic locus on chromosome 9q34.3 into primary miR-126 transcripts (pri-miR-126), which are processed into hairpin precursor molecules (pre-miR-126) and then further into the two different mature miRNA sequences [(miR-126, miR-126* (the complementary 'passenger strand' of miR-126)], which are incorporated into the RISC complex and guided to miR-126 target mRNAs to repress their expression. miR, microRNA; EGLF7, epidermal growth factor-like domain-containing gene domain-containing gene 7; RISC, RNA-induced silencing complex; $F g f 7$, epidermal growth factor-like domain-containing gene 7.

that of all-stage lung cancer, which suggests that circulating miRNAs can correctly distinguish every stage of lung cancer from controls correctly (56). In addition, the expression of miR-126 in serum of patients with asbestos-related NSCLC was comparable to that of patients with asbestos-unrelated NSCLC, which may indicate the diagnostic value of miR-126 in asbestos-related NSCLC (57). In contrast, another recent study mentioned that the levels of both serum and serum exosomal miR-126 in the early NSCLC group were significantly lower compared with those in the healthy control group but not significantly different from those in the benign lung lesions group (58). Thus far, the specific value of the role of miR-126 in early NSCLC and benign lung lesions still needs to be clarified further. Zhu et al (59) reported that circulating miRNAs, including miR-126, had a good diagnostic value for lung cancers, with a sensitivity of $60.7 \%$, a specificity of $92.5 \%$, and an AUC of $79.3 \%$. It is also worth noting that further logistic regression model analysis revealed that the combination of miR-126, miR-182, miR-183 and miR-210 with carcinoembryonic antigen substantially increased the diagnostic value, with an AUC of 96.5\%; sensitivity, $81.2 \%$; specificity, $100.0 \%$; and accuracy, $90.8 \%$ (59). The aforementioned results indicated that circulating miR-126, particularly in combination with multiple other miRNAs, may serve as a promising biomarker for the diagnosis of lung cancer $(56,59,60)$.

In addition, Bagheri et al (61) reported that a composite analysis of miR-145, miR-126 and miR-7 in sputum produced
$90 \%$ sensitivity and $90 \%$ specificity in distinguishing patients with NSCLC from controls. In addition, the combination of these three aforementioned miRNAs demonstrated an AUC value of $93 \%$, which was notably higher compared with the 53-88\% AUC values of the individual miRNAs (61). Of note, more studies demonstrated that bronchoalveolar lavage fluid exosomal miR-126 was highly expressed in lung adenocarcinoma tissues compared with normal tissue samples, suggesting that exosomal miR-126 may be a potential biomarker for NSCLC diagnosis $(14,62)$. These data reflect the promising value of different sources of miR-126 in the diagnosis of NSCLC patients.

\section{4. miR-126 and lung cancer prognosis}

In the past decade, a large number of studies have documented that miR-126 may also be a meaningful prognostic marker of lung cancer (19,21,63-65) (Table II). Recently, Xu et al (66) found that high plasma expression level of miR-126 in patients with lung cancer was associated with shorter disease-free survival [hazard ratios (HRs) of univariate Cox and multivariate Cox were 1.867 and 1.582, respectively; $95 \%$ confidence intervals (CIs) of univariate Cox and multivariate Cox were 1.386-2.515 and 1.158-2.161, respectively] and overall survival (OS) (HRs of univariate Cox and multivariate Cox were 1.706 and 1.320 , respectively; $95 \%$ CIs of univariate Cox and multivariate Cox were 1.218-2.388 and 0.932-1.817, respectively). 
Table I. Targets of miR-126 in lung cancer tumorigenesis.

\begin{tabular}{|c|c|c|c|c|}
\hline Experimental setting & Regulation of miR-126 & Targets & Effects & (Refs.) \\
\hline In vitro, $\mathrm{A} 549$ cells & $\begin{array}{l}\text { Overexpression } \\
\text { knockdown }\end{array}$ & STAT3 & $\begin{array}{l}\text { Proliferation, migration, cell cycle } \\
\text { entry, apoptosis susceptibility }\end{array}$ & (16) \\
\hline In vitro, $\mathrm{H} 1299$ cells & $\begin{array}{l}\text { Inhibitor, constructed by } \\
\text { Vipotion Co., Ltd. }\end{array}$ & $\begin{array}{l}\text { VEGF-A/ } \\
\text { VEGFR-2/ERK }\end{array}$ & Proapoptosis, antimetastasis & (17) \\
\hline In vitro, $\mathrm{H} 69 \mathrm{AR}$ cells & Overexpression & $\mathrm{PI} 3 \mathrm{~K} / \mathrm{AKT} / \mathrm{mTOR}$ & Growth of NSCLC cells & (18) \\
\hline In vitro, $\mathrm{H} 69 \mathrm{AR}$ cells & Overexpression & VCAM-1 & Growth of NSCLC cells & (18) \\
\hline In vitro, $\mathrm{A} 549$ cells & Overexpression & $\begin{array}{l}\text { Hub genes (VEGFA, } \\
\text { AKT1 and KRAS) }\end{array}$ & Invasion of NSCLC cells & (19) \\
\hline $\begin{array}{l}\text { In vitro, } \mathrm{A} 549, \mathrm{H} 1975, \\
\mathrm{H} 1299 \text { and } \mathrm{HCC} 827 \\
\text { cells In vivo, mice }\end{array}$ & Overexpression & CCR1 & $\begin{array}{l}\text { Growth, migration and invasion of } \\
\text { NSCLC cells } \\
\text { Reduced tumor growth }\end{array}$ & $(20)$ \\
\hline $\begin{array}{l}\text { In vitro, } \mathrm{A} 549, \mathrm{H} 1975, \\
\mathrm{H} 1299, \mathrm{H} 460 \text { and } \\
\text { SPC-A } 1 \text { cells }\end{array}$ & $\begin{array}{l}\text { Inhibitor, constructed by } \\
\text { Shanghai Genepharma } \\
\text { Co. Ltd. }\end{array}$ & SLC7A5 & $\begin{array}{l}\text { Angiogenesis, growth, migration and } \\
\text { invasion of NSCLC cells }\end{array}$ & $(21)$ \\
\hline $\begin{array}{l}\text { In vitro, } \mathrm{SPC}-\mathrm{A} 1, \\
\mathrm{LLC} \text { cells } \text { In vivo, mice }\end{array}$ & Overexpression & PI3K/AKT/Snail & $\begin{array}{l}\text { EMT } \\
\text { The weight of the Lewis lung } \\
\text { carcinoma-derived primary tumors } \\
\text { increased }\end{array}$ & $(27)$ \\
\hline In vitro, $\mathrm{A} 549$ cells & $\begin{array}{l}\text { Overexpression inhibitor, } \\
\text { not mentioned }\end{array}$ & PTEN/PI3K/AKT & Migration and invasion of NSCLC cells & $(10)$ \\
\hline $\begin{array}{l}\text { In vitro, } 4 \mathrm{~T} 1-\mathrm{M} \text { cells } \\
\text { In vivo, mice }\end{array}$ & Overexpression & SDF-1 $\alpha$ & $\begin{array}{l}\text { Recruitment of mesenchymal stem cells } \\
\text { Reduced tumor growth }\end{array}$ & (29) \\
\hline $\begin{array}{l}\text { In vitro, A549 cells } \\
\text { In vivo, mice }\end{array}$ & Overexpression & EGFL7, IRS-1 & $\begin{array}{l}\text { Angiogenesis } \\
\text { Inhibited tumor initiation }\end{array}$ & $(40)$ \\
\hline $\begin{array}{l}\text { In vitro, } \mathrm{A} 549, \mathrm{H} 1703, \\
\mathrm{H} 226, \mathrm{H} 358, \mathrm{HMVEC}, \\
\mathrm{NHBE} \text { and DMS53 cells } \\
\text { In vivo, mice }\end{array}$ & Overexpression & Crk & $\begin{array}{l}\text { Angiogenesis, growth, migration } \\
\text { and invasion of NSCLC cells } \\
\text { Inhibited tumor initiation }\end{array}$ & $(40,22)$ \\
\hline $\begin{array}{l}\text { In vitro, endothelial } \\
\text { cells In vivo, zebrafish }\end{array}$ & Knockdown & $\begin{array}{l}\text { Spred1/MAPK/VEGF } \\
\text { p3kr2/PI3K/VEGF }\end{array}$ & $\begin{array}{l}\text { Angiogenesis } \\
\text { Loss of vascular } \\
\text { integrity and hemorrhage during } \\
\text { embryonic development }\end{array}$ & $(50)$ \\
\hline
\end{tabular}

EGFL7, epidermal growth factor-like domain-containing gene 7; SLC7A5, solute carrier family 7 (cationic amino acid transporter, y+ system), member 5; NSCLC, non-small cell lung cancer; IRS-1, insulin receptor substrate 1; Crk, v-crk sarcoma virus CT10 oncogene homologue; Spred1, sprouty-related EVH1 domain-containing protein 1; MAPK, MAP kinase; VEGF, vascular endothelial growth factor; p3kr2, gene p3kr2; PI3K, phosphatidylinositol-3 protein kinase; STAT3, signal transducer and activator of transcription 3; VEGF-A, vascular endothelial growth factor A; ERK, extracellular protein kinase; AKT, protein kinase B; mTOR, mechanistic target of rapamycin; VCAM-1, vascular cell adhesion molecule 1; VEGFA, vascular endothelial growth factor A; AKT1, protein kinase B1; KRAS, Kirsten rat sarcoma viral oncogene homologue; CCR1, chemokine (C-C motif) receptor 1; EMT, epithelial-mesenchymal transition; PTEN, phosphatase and tensin homolog; SDF-1 $\alpha$, stromal cell-derived factor-1 $\alpha$; GRM8, glutamate receptor metabotropic 8; DACH1, dachshund family transcription factor 1; miR, microRNA.

In addition, not only was the expression of miR-126 apparently downregulated in tumor tissue compared with benign control tissue in NSCLCs, but the expression level was also significantly higher in NSCLCs with a tumor size of $\leq 3 \mathrm{~cm}$ compared with those with a tumor size of $>3 \mathrm{~cm}$, indicating the association between miR-126 expression and tumor size (67). In addition, Jusufovic et al (68) reported that low expression of miR-126 in lung cancer tissue was a negative prognostic factor for progression-free survival (PFS) (HR, 0.10; 95\% CI, 0.04-0.21) and OS (HR, 0.14; 95\% CI,0.06-0.31) in patients with NSCLC, which may be related to elevated MVD and lung cancer angiogenesis. Finally, Lønvik et al (69) discovered that intranuclear miRNA processing enzyme Drosha/miR-126 coexpression had a negative impact on the disease-specific survival rate. Additionally, lower expression of combined miRNAs (let-7b and miR-126) was closely associated with lower PFS time (HR,0.05; 95\% CI, 0.02-0.14) and OS time (HR, 0.05; 95\% CI, 0.02-0.16) in patients with NSCLC (68). However, the possible difference in the prognostic value between single miR-126 and coexpression of miR-126 with 
Table II. Biomarker value of miR-126 in the diagnosis and prognosis of lung cancer.

A, Diagnosis

Methods using

miR-126 as a

diagnostic

biomarker

Source

Specificity

Sensitivity

AUC

(\%)

Clinical stage

(Refs.)

\begin{tabular}{|c|c|c|c|c|c|c|}
\hline Single & Serum & 84.00 & 96.40 & 87.40 & $\begin{array}{l}\text { I-IV stage of lung cancer } \\
\text { NSCLC metastasis }\end{array}$ & $(55)$ \\
\hline Single & Serum plasma & 78.00 & 79.00 & 90.00 & I-II stage of lung cancer & $(56)$ \\
\hline miR-222/miR-126 & Serum & 70.00 & 80.00 & 66.00 & Asbestos-related NSCLC & $(57)$ \\
\hline Single & Serum exosomes & - & - & - & I-II stage of lung cancer & $(58)$ \\
\hline $\begin{array}{l}\text { Multiple miRNAs/ } \\
\text { miR-126 }\end{array}$ & Serum plasma & 87.00 & 87.00 & 94.00 & I-II stage of lung cancer & $(56)$ \\
\hline CEA/miR-126 & Serum exosomes & 100.00 & 81.20 & 96.50 & 0-IIIB stage of lung cancer & $(59)$ \\
\hline CEA/miR-126 & Serum exosomes & 92.50 & 88.50 & 97.50 & 0 -I stage of lung cancer & $(59)$ \\
\hline $\begin{array}{l}\text { Single, multiple } \\
\text { miRNAs/miR-126 }\end{array}$ & Sputum & 90.00 & 90.00 & 93.10 & I-IV stage of lung cancer & $(61)$ \\
\hline Exosomal & Tissue & - & - & - & I-II stage of lung cancer & (14) \\
\hline
\end{tabular}

B, Prognosis

\begin{tabular}{|c|c|c|c|c|c|c|}
\hline $\begin{array}{l}\text { Methods using } \\
\text { miR-126 as a } \\
\text { prognostic } \\
\text { biomarker }\end{array}$ & Source & $\begin{array}{l}\text { DFS HRs } \\
\text { (95\% CIs) }\end{array}$ & $\begin{array}{l}\text { PFS HRs } \\
\text { (95\% CIs) }\end{array}$ & $\begin{array}{c}\text { OS HRs } \\
\text { (95\% CIs) }\end{array}$ & Clinical stage & (Refs.) \\
\hline Single & Plasma & $\begin{array}{c}1.867 \\
(1.39-2.51)\end{array}$ & - & $\begin{array}{c}1.706 \\
(1.22-2.39)\end{array}$ & I-III stage of lung cancer & $(66)$ \\
\hline Single & Tissue & - & - & $\begin{array}{c}2.27 \\
(0.83-6.23)\end{array}$ & I-IV stage of lung cancer & (67) \\
\hline Single & Tissue & - & $\begin{array}{c}0.10 \\
(0.04-0.21)\end{array}$ & $\begin{array}{c}0.14 \\
(0.06-0.31)\end{array}$ & II-IV stage of lung cancer & (68) \\
\hline Drosha/miR-126 & Tissue & - & - & - & I-III stage of lung cancer & (69) \\
\hline let-7b/miR-126 & Tissue & - & $\begin{array}{c}0.05 \\
(0.02-0.14)\end{array}$ & $\begin{array}{c}0.05 \\
(0.02-0.16)\end{array}$ & II-IV stage of lung cancer & (68) \\
\hline
\end{tabular}

AUC, area under the curve; NSCLC, non-small cell lung cancer; CEA, carcinoembryonic antigen; DFS, disease-free survival; HRs, Hazard ratios; CIs, confidence intervals; PFS, progression-free survival; OS, overall survival; Drosha, intranuclear miRNA processing enzyme Drosha; miRNA, microRNA.

other factors in patients with NSCLC prognosis needs to be further elucidated. In brief, the aforementioned results may contribute to proving the prognostic value of miR-126 in lung cancer.

\section{5. miR-126 as a potential target for lung cancer therapy}

Currently, some drugs for treating lung cancer target the VEGF signaling pathway (70-72). VEGF signaling can promote the growth of vascular endothelial cells and vascular repair through connexin 43 (17,73-78). miR-126 was reported as one of the most important regulators of signaling for angiogenic growth factors, such as VEGF, fibroblast growth factor, insulin like growth factor and endothelial growth factor that manipulate vascular integrity and angiogenesis, indicating its potential value in lung cancer treatment $(40,53)$ (Table III). For instance, Sun et al (40) first reported that the expression of EGFL7 increased significantly in vitro and in vivo after transfection with a miR-126 overexpression plasmid that targets EGFL7. Subsequently, miR-126 restoration led to a reduction in the number of A549 cell initiating differentiation, accompanied by significant inhibition of tumor cell proliferation in vitro and tumor formation in vivo (40). Recently, Jia et al (27) used a xenograft Lewis lung carcinoma model in C57BL/6 mice to detect the role of miR-126 in lung cancer metastasis and found that the stable ectopic expression of miR-126 significantly suppressed the formation of lung metastases following the surgical removal of the primary tumors. Meanwhile, decreased 
Table III. miR-126 as a potential target for lung cancer therapy.

A, Methods targeting miRNA-126

\begin{tabular}{llll}
\hline Expression of miR-126 & Experimental setting & Targets & \multicolumn{1}{c}{ Effects } \\
\hline Upregulated & In vitro, in vivo & EGFL7 & $\begin{array}{l}\text { Inhibition on initiating cell } \\
\text { differentiation, tumour cells } \\
\text { proliferation and tumor formation }\end{array}$ \\
Upregulated & In vitro, in vivo & PI3K/AKT/Snail & $\begin{array}{l}\text { Inhibition on lung cancer metastasis, } \\
\text { EMT } \quad \text { (27) }\end{array}$ \\
Upregulated & In vitro & VEGF/PI3K/AKT/MRP1 & $\begin{array}{l}\text { Promoting the sensitivity of NSCLC } \\
\text { cells to anticancer agents } \\
\text { Upregulated }\end{array}$ \\
& In vivo & PI3K-AKT & $\begin{array}{l}\text { Promoting ionizing } \\
\text { radiation-induced apoptosis }\end{array}$ \\
\hline
\end{tabular}

B, Methods using miR-126 differently

\begin{tabular}{llll}
\hline Expression of miR-126 & Experimental setting & Targets & Effects \\
\hline lncRNA-PVT1-5/ miR-126 & In vitro & SLC7A5 & Inhibition on tumorigenesis \\
miR-126-231-Exo & In vitro, in vivo & PTEN/PI3K/AKT & Inhibition on tumorigenesis \\
\hline
\end{tabular}

C, Other drugs/methods

\begin{tabular}{llll}
\hline Expression of miR-126 & Experimental setting & Targets & \multicolumn{1}{c}{ Effects } \\
\hline Cryptotanshinone & In vitro & STAT3 & Inhibition of the growth of lung \\
cancer cells & (16) \\
TBMS1 & In vitro & VEGF-A/VEGFR-2/ERK & $\begin{array}{l}\text { Pro-apoptosis, anti-metastasis } \\
\text { Inhibition of tumorigenesis }\end{array}$ \\
CT-PRFA & In vivo & - & (17) \\
\hline
\end{tabular}

EGFL7, epidermal growth factor-like domain-containing gene 7; PI3K, phosphatidylinositol-3; AKT, protein kinase B; EMT, epithelial-mesenchymal transition; NSCLC, non-small cell lung cancer; VEGF, vascular endothelial growth factor; MRP1, resistance-associated protein 1; lncRNA-PVT1-5, long non-coding RNA-PVT1-5; SLC7A5, solute carrier family 7 (cationic amino acid transporter, y+ system), member 5; miR-126-231-Exo, miR-126 loaded into 231-Exo; PTEN, phosphatase and tensin homologue; STAT3, signal transducer and activator of transcription 3; TBMS1, tubeimoside-1; VEGF-A, vascular endothelial growth factor A; VEGFR-2, vascular endothelial growth factor receptor 2; ERK, extracellular protein kinase; CT-PRFA, computed tomography-guided percutaneous radio frequency ablation, miRNA, microRNA.

expression of EMT markers was observed in the miR-126 overexpression group compared with the negative control group. The results of the aforementioned study indicated that miR-126 could suppress EMT and metastasis of lung cancer cells by targeting PI3K/AKT/Snail signaling (27). Enhanced expression of miR-126 also increased the sensitivity of NSCLC cells to anticancer agents through the negative regulation of the VEGF/PI3K/AKT/resistance-associated protein 1 signaling pathway (3). Notably, some studies also demonstrated that miR-126 could promote ionizing radiation-induced apoptosis through the PI3K-AKT pathway in lung cancer $(79,80)$.

In addition to the studies mentioned above, miR-126 was also regarded as a crucial regulator involved in the effect of other factors in lung cancer (Table III). For instance, Li et al (81) reported that long non-coding RNA-PVT1-5 (1ncRNA-PVT1-5) may act as a competing endogenous RNA for miR-126 to promote cell proliferation by regulating the miR-126/SLC7A5 pathway, suggesting that the IncRNA-PVT1-5/miR-126/SLC7A5 regulatory network may shed light on tumorigenesis in lung cancer. Furthermore, exosomes are a delivery systems with low immunogenicity and toxicity that are not recognized by the mononuclear phagocyte system (82). These special properties of exosomes make them appropriate to serve as targeted delivery systems in cancer therapy $(83,84)$. Recently, Nie et al $(85)$ demonstrated that miR-126 loaded into 231-Exo (miRNA-231-Exo) led to an effective inhibitory effect on proliferation and migration in A549 lung cancer cells via the interruption of the PTEN/PI3K/AKT signaling pathway. miR-126-laden 231-Exo, which can effectively escape innate immune cells, also demonstrated a potent cancer inhibition effect in a lung cancer metastasis model in mice.

In addition, miR-126 also serves a vital role when other therapeutic approaches using other drugs are used in lung cancer. For instance, cryptotanshinone is an important inhibitor of the development of lung cancer cells (86). The expression levels of miR-126 were upregulated by treatment with cryptotanshinone in A549 cells (87). In addition, one 


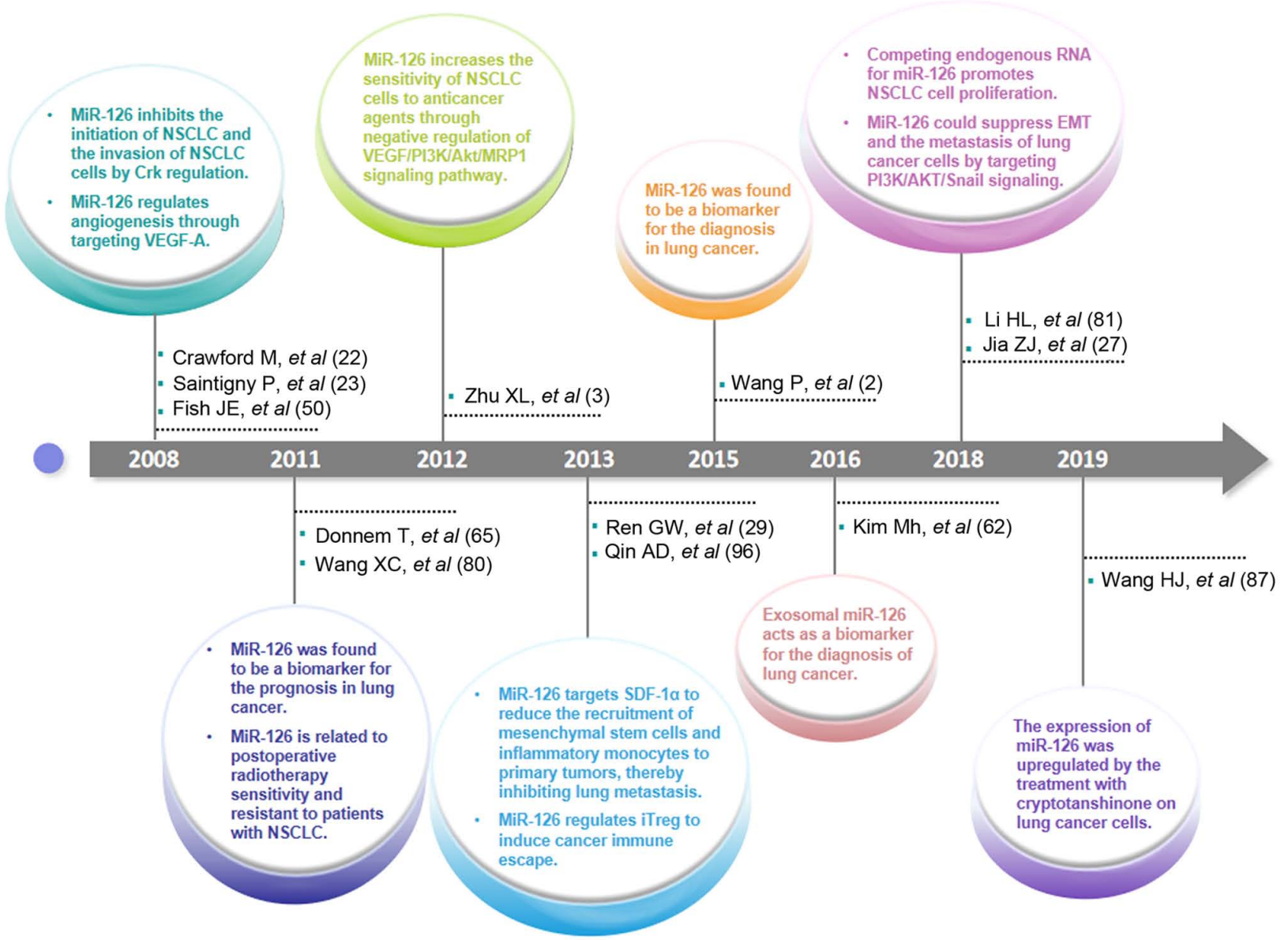

Figure 2. Highlights in the research progress of miR-126 in lung cancer. In 2008, it was first mentioned that miR-126 has a significant role in the angiogenesis, initiation and progression of lung cancer, as well as lung cancer cell invasion. MiR-126 was viewed as a prognostic biomarker in lung cancer and first reported that it is related to postoperative radiotherapy sensitivity and resistant to patients with NSCLC in 2011. Afterwards, the role of miR-126 in the sensitivity of NSCLC cells to anticancer agents was uncovered in 2012. In 2013, a seminal publication reported the role of miR-126 in the recruitment of mesenchymal stem cells and inflammatory monocytes in lung metastasis. Due to the discovery of the role of miR-126 in the lung tumor microenvironment, its role in cancer immune escape which is mediated by iTregs was found. Thereafter, miR-126 and exosomal miR-126 were perceived as diagnostic biomarkers for lung cancer since 2015 and 2016, respectively. In 2018, reports about competing endogenous RNA for miR-126 promoting NSCLC cell proliferation and the role of miR-126 in EMT and the metastasis of lung cancer cells were published. In 2019, changes in the expression level of miR-126 in lung cancer cells following treatment with cryptotanshinone were reported. miR, microRNA; NSCLC, non-small cell lung cancer; EMT, epithelial-mesenchymal transition; Crk, v-crk sarcoma virus CT10 oncogene homologue; VEGF, vascular endothelial growth factor; VEGF-A, vascular endothelial growth factor A; MRP1, MRP1, resistance-associated protein 1; SDF-1 $\alpha$, stromal cell-derived factor- $1 \alpha$; i-Treg, induced T regulatory cell; AKT, protein kinase B; PI3K, phosphatidylinositol-3 protein kinase.

\section{MiRNA-TF-target network}

The relationships among target molecules of miR-126 in the development of lung cancer remain to be further elucidated.

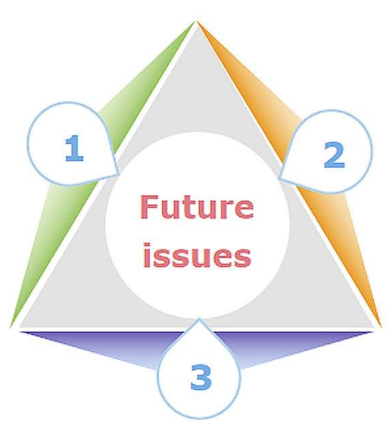

MiR-126 and therapy

- How to effectively introduce miR-126 into lung cancer cells in vivo?

- How to monitor the side effects of miR-126 in lung cancer gene therapy?

- What is the role of miR-126 in the immune response of lung cancer?

Figure 3. A schematic of future issues associated with miR-126 in lung cancer. The major issues may be from three important fields: The target network, regulation of miR-126 expression and therapy in lung cancer. miR, microRNA; TF, transcription factors. 
new study demonstrated that tubeimoside-1 (TBMS1) could elevate miR-126 expression, whereas overexpressing miR-126 inactivated the VEGF-A/VEGFR-2/ERK signaling pathway, which promoted proapoptotic and antimetastatic effects in NCI-H1299 cells (17). The aforementioned study may offer a theoretical foundation for miR-126 serving a critical role in the treatment of TBMS1 in lung cancer (17). Similarly, other researchers reported that computed tomography-guided percutaneous radio frequency ablation was an effective treatment for primary NSCLCs and secondary lung tumors in hepatocellular carcinoma; the efficacy of ablation may be related to its ability to normalize deregulated expression of miR-126 (88).

\section{Conclusion}

To date, important progress in the research on the role of miR-126 in the tumorigenesis, diagnosis, prognosis and therapy of lung cancer has been achieved (Fig. 2). However, some scientific issues remain to be further elucidated (Fig. 3). Firstly, the relationships among different target molecules of miR-126 in the development of lung cancer have not yet been clearly elucidated. Notably, Barshack et al (89) demonstrated that miR-126 was significantly upregulated in liver cancer lung metastasis, indicating that miR-126 may play different roles through distinct targets in some special types of cancer $(90,91)$. For instance, in lung tumor tissues, Tafsiri et al (90) reported that miR-126 was downregulated in 15 out of 18 adenocarcinoma samples, but there was no significant correlation between squamous cell carcinoma and expression of miR-126. Chen et al (91) demonstrated the result of pathway enrichment analysis of the target genes that the target genes of miR-126 in NSCLC [FOXO3, phosphoinositide 3-kinase catalytic subunit $\delta$ (PIK3CD) and PIK3R2] were different from those in colorectal cancer (Bcl-2, PIK3CD, PIK3R2). The underlying molecular mechanisms may be related to the involvement of miR-126 in an miRNA-TF-target network that contains PIK3CD, PIK3R2, forkhead box protein O3, plexin B2 and tuberous sclerosis 1 (91). Secondly, some challenges need to be further addressed. For example, it is unclear how to effectively introduce miR-126 into lung cancer cells in vivo and how to monitor the side effects of miR-126 in lung cancer gene therapy. In particular, some evidences have shown that miR-126 also plays a vital role in the function of immune cells including effector T cells and regulatory T cells (Tregs) (92-96). Additionally, miR-126 is also likely to be involved in $\mathrm{CD}^{+} \mathrm{T}$ cell function (97). Hence, further investigation of the role of miR-126 in lung cancer, including in the immune response, may be valuable for the progression of miRNA-based immunotherapy against lung cancer.

\section{Acknowledgements}

No applicable.

\section{Funding}

The present study was supported by the Program for High level Innovative Talents in the Guizhou Province (grant no. QKH-RC-2016-4031), the National Natural Science Foundation of China (grant no. 31760258), the Program for
New Century Excellent Talents in University, Ministry of Education of China (grant no. NCET-12-0661), the Program for Excellent Young Talents of Zunyi Medical University (grant no. 15ZY-001) and the Project of Guizhou Provincial Department of Science and Technology (grant no. 2009C491).

\section{Availability of data and materials}

Data sharing is not applicable to this article, as no datasets were generated or analyzed during the current study.

\section{Authors' contributions}

QC designed and wrote the study. SC and YZ designed the the study. JZ wrote the manuscript. LX conceived, designed and wrote the manuscript. All authors have read and approved this manuscript.

\section{Ethics approval and consent to participate}

Not applicable.

\section{Patient consent for publication}

Not applicable.

\section{Competing interests}

The authors declare that they have no competing interests.

\section{Reference}

1. Lam S, Chari R, Lockwood W, Lam W, MacAulay C, Sin D, Gazdar A, Khoury J, Yao RS and You M: Progress in lung cancer chemoprevention. Cancer Epidem Biomar 4: 46-52, 2006.

2. Wang P, Yang D, Zhang H, Wei X, Ma T, Cheng Z, Hong Q, Hu J, Zhou H, Song Y, et al: Early detection of lung cancer in serum by a panel of microRNA biomarkers. Clin Lung Cancer 16: 313-319. el, 2015.

3. Zhu X, Li H, Long L, Hui L, Chen H, Wang X, Shen H and $\mathrm{Xu} \mathrm{W}$ : MiR-126 enhances the sensitivity of non-small cell lung cancer cells to anticancer agents by targeting vascular endothelial growth factor A. Acta Biochim Biophys Sin (Shanghai) 44: 519-526, 2012.

4. Latronico MV, Catalucci D and Condorelli G: Emerging role of microRNAs in cardiovascular biology. Circ Res 101: 1225-1236, 2007.

5. Zhang C: MicroRNomics: A newly emerging approach for disease biology. Physiol Genomics 33: 139-147, 2008.

6. Peng Y, Chao FF, Cai YP, Teng W and Qiu CG: MiR-126 inhibits the proliferation of myocardial fibroblasts by regulating EGFL7-mediated EGFR signal pathway. Int J Clin Exp Med 10: 6158-6166, 2017

7. Liu F, Zhang H, Lu S, Wu Z, Zhou L, Cheng Z, Bai Y, Zhao J, Zhang Q and Mao H: Quantitative assessment of gene promoter methylation in non-small cell lung cancer using methylation-sensitive high-resolution melting. Oncol Lett 15: 7639-7648, 2018.

8. Saito Y, Friedman JM, Chihara Y, Egger G, Chuang JC and Liang G: Epigenetic therapy upregulates the tumor suppressor microRNA-126 and its host gene EGFL7 in human cancer cells. Biochem Biophys Res Commun 379: 726-731, 2009.

9. Wei L, Chen Z, Cheng N, Li X, Chen J, Wu D, Dong M and Wu X: MicroRNA-126 inhibit viability of colorectal cancer cell by repressing mTOR induced apoptosis and autophagy. Onco Targets Ther 13: 2459-2468, 2020.

10. Song L, Li D, Gu Y, Wen ZM, Jie J, Zhao D and Peng LP: MicroRNA-126 targeting PIK3R2 inhibits NSCLC A549 cell proliferation, migration, and invasion by regulation of PTEN/PI3K/AKT pathway. Clin Lung Cancer 17: e65-e75, 2016. 
11. Switlik WZ, Karbownik MS, Suwalski M, Kozak J and Szemraj J Serum miR-210-3p as a potential noninvasive biomarker of lung adenocarcinoma: A preliminary study. Genet Test Mol Biomarkers 23: 353-358, 2019.

12. Świtlik W, Karbownik MS, Suwalski M, Kozak J and Szemraj J: MiR-30a-5p together with miR-210-3p as a promising biomarker for non-small cell lung cancer: A preliminary study. Cancer Biomark 21: 479-488, 2018.

13. Zheng W, Zhou Y, Lu J, Xu H, Lei L, Chen C, Zhao J and Xu L: The prognostic value of miR-126 expression in non-small-cell lung cancer: A meta-analysis. Cancer Cell Int 17: 71, 2017.

14. Kim JE, Eom JS, Kim WY, Jo EJ, Mok J, Lee K, Kim KU, Park HK, Lee MK and Kim MH: Diagnostic value of microRNAs derived from exosomes in bronchoalveolar lavage fluid of early-stage lung adenocarcinoma: A pilot study. Thorac Cancer 9: 911-915, 2018.

15. Chen P, Gu YY, Ma FC, He RQ, Li ZY, Zhai GQ, Lin X, $\mathrm{Hu} \mathrm{XH}, \mathrm{Pan} \mathrm{LJ}$ and Chen G: Expression levels and co-targets of miRNA-126-3p and miRNA-126-5p in lung adenocarcinoma tissues: An exploration with RT-qPCR, microarray and bioinformatic analyses. Oncol Rep 41: 939-953, 2019.

16. Zhang Z, Wang J, Cheng J and Yu X: Effects of miR-126 on the STAT3 signaling pathway and the regulation of malignant behavior in lung cancer cells. Oncol Lett 15: 8412-8416, 2018.

17. Shi H, Bi H, Sun X, Dong H, Jiang Y, Mu H, Liu G, Kong W, Gao R and Su J: Antitumor effects of Tubeimoside-1 in NCI-H1299 cells are mediated by microRNA-126-5p-induced inactivation of VEGF-A/VEGFR-2/ERK signaling pathway. Mol Med Rep 17: 4327-4336, 2018.

18. Chen M, Peng W, Hu S and Deng J: MiR-126/VCAM-1 regulation by naringin suppresses cell growth of human non-small cell lung cancer. Oncol Lett 16: 4754-4760, 2018.

19. Song F, Xuan Z, Yang X, Ye X, Pan Z and Fang Q: Identification of key microRNAs and hub genes in non-small-cell lung cancer using integrative bioinformatics and functional analyses. J Cell Biochem 121: 2690-2703, 2020.

20. Liu R, Zhang YS, Zhang S, Cheng ZM, Yu JL, Zhou S and Song J: MiR-126-3p suppresses the growth, migration and invasion of NSCLC via targeting CCR1. Eur Rev Med Pharmacol Sci 23: 679-689, 2019.

21. Wang J, Ding M, Zhu H, Cao Y and Zhao W: Up-regulation of long noncoding RNA MINCR promotes non-small cell of lung cancer growth by negatively regulating miR-126/SLC7A5 axis. Biochem Biophys Res Commun 508: 780-784, 2019.

22. Crawford M, Brawner E, Batte K, Yu L, Hunter MG, Otterson GA, Nuovo G, Marsh CB and Nana-Sinkam SP: MicroRNA-126 inhibits invasion in non-small cell lung carcinoma cell lines. Biochem Biophys Res Commun 373: 607-612, 2008.

23. Saintigny P, Ren H, Zou XC and Mao L: MicroRNA (miRNA) species differentially expressed between immortalized normal bronchial epithelial cells and non-small cell lung. Cancer Res 373: 607-612, 2008.

24. Song L, Li XX, Liu XY, Wang Z, Yu Y, Shi M, Jiang B and He XP: EFEMP2 suppresses the invasion of lung cancer cells by inhibiting epithelial-mesenchymal transition (EMT) and down-regulating MMPs. Onco Targets Ther 13: 1375-1396, 2020.

25. Chen J, Tong W, Liao M and Chen D: Inhibition of arachidonate lipoxygenase 12 targets lung cancer through inhibiting EMT and suppressing RhoA and NF- $\kappa$ B activity. Biochem Biophys Res Commun 524: 803-809, 2020.

26. Tao L, Shu-Ling W, Jing-Bo H, Ying Z, Rong H, Xiang-Qun L, Wen-Jie C and Lin-Fu Z: MiR-451a attenuates doxorubicin resistance in lung cancer via suppressing epithelial mesenchymal transition (EMT) through targeting c-Myc. Biomed Pharmacother 125: 109962, 2020.

27. Jia Z, Zhang Y, Xu Q, Guo W and Guo A: MiR-126 suppresses epithelial-to-mesenchymal transition and metastasis by targeting $\mathrm{PI} 3 \mathrm{~K} / \mathrm{AKT} /$ Snail signaling of lung cancer cells. Oncol Lett 15: 7369-7375, 2018

28. Yang X, Chen BB, Zhang MH and Wang XR: MicroRNA-126 inhibits the proliferation of lung cancer cell line A549. Asian Pac J Trop Med 8: 239-242, 2015.

29. Ren G and Kang Y: A one-two punch of miR-126/126* against metastasis. Nat Cell Biol 15: 231-233, 2013

30. Wang Z, Lu B, Sun L, Yan X and Xu J: Identification of candidate genes or microRNAs associated with the lymph node metastasis of SCLC. Cancer Cell Int 18: 161, 2018.

31. Wang J, Chen J, Guo Y, Wang B and Chu H: Strategies targeting angiogenesis in advanced non-small cell lung cancer. Oncotarget 8: 53854-53872, 2017.
32. Li FJ, Huang J, Ji D, Meng Q, Wang C, Chen S, Wang X, Zhu Z, Jiang C, Shi Y, et al: Azithromycin effectively inhibits tumor angiogenesis by suppressing vascular endothelial growth factor receptor 2-mediated signaling pathways in lung cancer. Oncol Lett 14: 89-96, 2017.

33. Lauridant G, Kotecki N, Pannier D and Dansin E: The role of angiogenesis inhibitors in the treatment of lung cancer. Oncologie 18: 409-418, 2016

34. Tian RH, Wu X, Liu X, Yang JW, Ji HL and Yan YJ: The role of angiogenesis inhibitors in the treatment of elderly patients with advanced non-small-cell lung cancer: A meta-analysis of eleven randomized controlled trials. J Cancer Res Ther 12: 571-575, 2016.

35. Wang S, Aurora AB, Johnson BA, Qi X, McAnally J, Hill JA, Richardson JA, Bassel-Duby R and Olson EN: The endothelial-specific microRNA miR-126 governs vascular integrity and angiogenesis. Dev Cell 15: 261-271, 2008.

36. Hong G, Kuek V, Shi J, Zhou L, Han X, He W, Tickner J, Qiu H, Wei Q and Xu J: EGFL7: Master regulator of cancer pathogenesis, angiogenesis and an emerging mediator of bone homeostasis. J Cell Physiol 233: 8526-8537, 2018.

37. Johnson L, Huseni M, Smyczek T, Lima A, Yeung S, Cheng JH, Molina R, Kan D, De Mazière A, Klumperman J, et al: Anti-EGFL7 antibodies enhance stress-induced endothelial cell death and anti-VEGF efficacy. J Clin Invest 123: 3997-4009, 2013.

38. Usuba R, Pauty J, Soncin F and Matsunaga YT: EGFL7 regulates sprouting angiogenesis and endothelial integrity in a human blood vessel model. Biomaterials 197: 305-316, 2019.

39. Monaco F, Gaetani S, Alessandrini F, Tagliabracci A, Bracci M, Valentino M, Neuzil J, Amati M, Bovenzi M, Tomasetti M and Santarelli L: Exosomal transfer of miR-126 promotes the anti-tumour response in malignant mesothelioma: Role of miR-126 in cancer-stroma communication. Cancer Lett 463: 27-36, 2019.

40. Sun Y, Bai Y, Zhang F, Wang Y, Guo Y and Guo L: MiR-126 inhibits non-small cell lung cancer cells proliferation by targeting EGFL7. Biochem Biophys Res Commun 391: 1483-1489, 2010.

41. Shen X, Zhi Q, Wang Y, Li Z, Zhou J and Huang J: Hypoxia induces multidrug resistance via enhancement of epidermal growth Factor-like domain 7 expression in non-small lung cancer cells. Chemotherapy 62: 172-180, 2017.

42. Caporali S, Amaro A, Levati L, Alvino E, Lacal PM, Mastroeni S, Ruffini F, Bonmassar L, Antonini Cappellini GC, Felli N, et al: MiR-126-3p down-regulation contributes to dabrafenib acquired resistance in melanoma by up-regulating ADAM9 and VEGF-A. J Exp Clin Cancer Res 38: 272, 2019.

43. Di Martino S, Acierno C and Licito A: Experimental study on the prevention of liver cancer angiogenesis via miR-126. Promising results for targeted therapy. Eur Rev Med Pharmacol Sci 22: $853-855,2018$.

44. Pishavar E and Behravan J: MiR-126 as a therapeutic agent for diabetes mellitus. Curr Pharm Des 23: 3309-3314, 2017.

45. Zhou F, Jia X, Yang Y, Yang Q, Gao C, Hu S, Zhao Y, Fan Y and Yuan X: Nanofiber-mediated microRNA-126 delivery to vascular endothelial cells for blood vessel regeneration. Acta Biomater 43: 303-313, 2016.

46. Dong G, Lin XH, Liu HH, Gao DM, Cui JF, Ren ZG and Chen RX: Intermittent hypoxia alleviates increased VEGF and Pro-angiogenic potential in liver cancer cells. Oncol Lett 18: 1831-1839, 2019.

47. Gu C, Zou S, He C, Zhou J, Qu R, Wang Q, Qi J, Zhou M, Yan S and Ye Z: Long non-coding RNA CCAT1 promotes colorectal cancer cell migration, invasiveness and viability by upregulating VEGF via negative modulation of microRNA-218. Exp Ther Med 19: 2543-2550, 2020.

48. Yoon NA, Jung SJ, Choi SH, Ryu JH, Mani M, Lee UH, Vo MT, Jeon DY, Chung SW, Ju Lee B, et al: DRG2 supports the growth of primary tumors and metastases of melanoma by enhancing VEGF-A expression. FEBS J 287: 2070-2086, 2020.

49. Boudria A, Abou Faycal C, Jia T, Gout S, Keramidas M, Didier C, Lemaître N, Manet S, Coll JL, Toffart AC, et al: $\mathrm{VEGF}_{165} \mathrm{~b}$, a splice variant of VEGF-A, promotes lung tumor progression and escape from anti-angiogenic therapies through a $\beta 1$ integrin/VEGFR autocrine loop. Oncogene 38: 1050-1066, 2019.

50. Fish JE, Santoro MM, Morton SU, Yu S, Yeh RF, Wythe JD, Ivey KN, Bruneau BG, Stainier DY and Srivastava D: MiR-126 regulates angiogenic signaling and vascular integrity. Dev Cell 15: 272-284, 2008. 
51. Qu Y, Wu J, Deng JX, Zhang YP, Liang WY, Jiang ZL, Yu QH and Li J: MicroRNA-126 affects rheumatoid arthritis synovial fibroblast proliferation and apoptosis by targeting PIK3R 2 and regulating PI3K-AKT signal pathway. Oncotarget 7: 74217-74226, 2016.

52. Ye L, Peng Y, Mo J and Yao Y: MiR-126 enhances VEGF expression in induced pluripotent stem cell-derived retinal neural stem cells by targeting spred-1. Int J Clin Exp Pathol 11: 1023-1030, 2018.

53. Yücel EI and Sahin M: Fenretinide reduces angiogenesis by downregulating CDH5, FOXM1 and eNOS genes and suppressing microRNA-10b. Mol Biol Rep 47: 1649-1658, 2020.

54. Liu X, Tufman A, Behr J, Kiefl R, Goldmann T and Huber RM: Role of the erythropoietin receptor in lung cancer cells: Erythropoietin exhibits angiogenic potential. J Cancer 11: 6090-6100, 2020.

55. Shang AQ, Xie YN, Wang J, Sun L, Wei J, Lu WY, Lan JY, Wang WW, Wang L and Wang LL: Predicative values of serum microRNA-22 and microRNA-126 levels for non-small cell lung cancer development and metastasis: A case-control study. Neoplasma 64: 453-459, 2017.

56. Yang Y, Hu Z, Zhou Y, Zhao G, Lei Y, Li G, Chen S, Chen K, Shen Z, Chen X, et al: The clinical use of circulating microRNAs as non-invasive diagnostic biomarkers for lung cancers Oncotarget 8: 90197-90214, 2017.

57. Santarelli L, Gaetani S, Monaco F, Bracci M, Valentino M, Amati M, Rubini C, Sabbatini A, Pasquini E, Zanotta N, et al: Four-miRNA signature to identify asbestos-related lung malignancies. Cancer Epidemiol Biomarkers Prev 28: 119-126, 2019.

58. Wu Q, Yu L, Lin X, Zheng Q, Zhang S, Chen D, Pan X and Huang Y: Combination of serum miRNAs with serum exosomal miRNAs in early diagnosis for non-small-cell lung cancer. Cancer Manag Res 12: 485-495, 2020.

59. Zhu W, Zhou K, Zha Y, Chen D, He J, Ma H, Liu X, Le H and Zhang Y: Diagnostic value of serum miR-182, miR-183, miR-210, and miR-126 levels in patients with early-stage non-small cell lung cancer. PLoS One 11: e0153046, 2016.

60. Wang W, Ding M, Duan X, Feng X, Wang P, Jiang Q, Cheng Z, Zhang W, Yu S, Yao W, et al: Diagnostic value of plasma microRNÂs for lung cancer using support vector machine model. J Cancer 10: 5090-5098, 2019.

61. Bagheri A, Khorshid HRK, Tavallaie M, Mowla SJ, Sherafatian M, Rashidi M, Zargari M, Boroujeni ME and Hosseini SM: A panel of noncoding RNAs in non-small-cell lung cancer. J Cell Biochem: Nov 28, 2018 doi: 10.1002/jcb.28111 (Epub ahead of print).

62. Kim MH, Jo EJ, Eom JS, Mok JH, Ki KL, Kim U, Park HK and Lee MK: Diagnostic value of microRNAs derived exosomes from bronchoalveolar lavage fluid in early stage lung adenocarcinoma. Chest 150: 703A, 2016.

63. Ulivi P, Petracci E, Marisi G, Baglivo S, Chiari R, Billi M, Canale M, Pasini L, Racanicchi S, Vagheggini A, et al: Prognostic role of circulating miRNAs in early-stage non-small cell lung cancer. J Clin Med 8: 131, 2019.

64. Chen SW, Wang TB, Tian YH and Zheng YG: Down-regulation of microRNA-126 and microRNA-133b acts as novel predictor biomarkers in progression and metastasis of non small cell lung cancer. Int J Clin Exp Pathol 8: 14983-14988, 2015.

65. Donnem T, Lonvik K, Eklo K, Berg T, Sorbye SW, Al-Shibli K, Al-Saad S, Andersen S, Stenvold H, Bremnes RM and Busund LT: Independent and tissue-specific prognostic impact of miR-126 in nonsmall cell lung cancer: Coexpression with vascular endothelial growth factor-A predict poor survival. Cancer 117: 3193-3200, 2011.

66. $\mathrm{Xu} \mathrm{X}$, Zhu S, Tao Z and Ye S: High circulating miR-18a, miR-20a, and miR-92a expression correlates with poor prognosis in patients with Non-small cell lung cancer. Cancer Med 7: 21-31, 2018.

67. Kim MK, Jung SB, Kim JS, Roh MS, Lee JH, Lee EH and Lee HW: Expression of microRNA miR-126 and miR-200c is associated with prognosis in patients with non-small cell lung cancer. Virchows Arch 465: 463-471, 2014

68. Jusufovic E, Rijavec M, Keser D, Korošec P, Sodja E, Iljazović E, Radojević Z and Košnik M: Let-7b and miR-126 are down-regulated in tumor tissue and correlate with microvessel density and survival outcomes in non-small-cell lung cancer. PLoS One 7: e45577, 2012

69. Lønvik K, Sørbye SW, Nilsen MN and Paulssen RH: Prognostic value of the MicroRNA regulators Dicer and Drosha in non-small-cell lung cancer: Co-expression of Drosha and miR-126 predicts poor survival. BMC Clin Pathol 14: 45, 2014.
70. Shi H, Bi H, Sun X, Dong H, Jiang Y, Mu H, Li W, Liu G, Gao R and Su J: Tubeimoside-1 inhibits the proliferation and metastasis by promoting miR-126-5p expression in non-small cell lung cancer cells. Oncol Lett 16: 3126-3134, 2018.

71. Rai MK, Goyal R, Bhutani MK, Kaneria J, Mahendru K and Sharma N: Efficacy and safety profile of combined targeted therapy against Egfr and Vegf in patients with previously treated advanced non-small-cell lung cancer: A systematic review and meta-analysis. Value Health 18: A430, 2015.

72. Yin W, Zhu J, Gonzalez-Rivas D, Okumura M, Rocco G, Pass H, Jiang $G$ and Yang Y: Construction of a novel bispecific antibody to enhance antitumor activity against lung cancer. Adv Mater 30: e1805437, 2018

73. Leung DW, Cachianes G, Kuang WJ, Goeddel DV and Ferrara N: Vascular endothelial growth factor is a secreted angiogenic mitogen. Science 246: 1306-1309, 1989.

74. Sheikh AM, Yano S, Mitaki S, Haque MA, Yamaguchi S and Nagai A: A Mesenchymal stem cell line (B10) increases angiogenesis in a rat MCAO model. Exp Neurol 311: 182-193, 2019.

75. Kong Z, Hong Y, Zhu J, Cheng X and Liu Y: Endothelial progenitor cells improve functional recovery in focal cerebral ischemia of rat by promoting angiogenesis via VEGF. J Clin Neurosci 55: 116-121, 2018.

76. Ruan W,Zhao F, Zhao S, Zhang L, Shi L and Pang T: Knockdown of long noncoding RNA MEG3 impairs VEGF-stimulated endothelial sprouting angiogenesis via modulating VEGFR2 expression in human umbilical vein endothelial cells. Gene 649: 32-39, 2018.

77. Melincovici CS, Boşca AB, Şuşman S, Mărginean M, Mihu C, Istrate M, Moldovan IM, Roman AL and Mihu CM: Vascular endothelial growth factor (VEGF)-key factor in normal and pathological angiogenesis. Rom J Morphol Embryol 59: 455-467, 2018.

78. Li L, Liu H, Xu C, Deng M, Song M, Yu X, Xu S and Zhao X: VEGF promotes endothelial progenitor cell differentiation and vascular repair through connexin 43. Stem Cell Res Ther 8: 237, 2017.

79. Long L, Zhang X, Bai J,Li Y, Wang X and Zhou Y: Tissue-specific and exosomal miRNAs in lung cancer radiotherapy: From regulatory mechanisms to clinical implications. Cancer Manag Res 11: 4413-4424, 2019.

80. Wang XC, Du LQ, Tian LL, Wu HL, Jiang XY, Zhang H, Li DG, Wang YY, Wu HY, She Y, et al: Expression and function of miRNA in postoperative radiotherapy sensitive and resistant patients of non-small cell lung cancer. Lung Cancer 72: 92-99, 2011.

81. Li H, Chen S, Liu J, Guo X, Xiang X, Dong T, Ran P, Li Q, Zhu B, Zhang X, et al: Long non-coding RNA PVT1-5 promotes cell proliferation by regulating miR-126/SLC7A5 axis in lung cancer. Biochem Biophys Res Commun 495: 2350-2355, 2018.

82. Fortunato O, Gasparini P, Boeri M and Sozzi G: Exo-miRNAs as a new tool for liquid biopsy in lung cancer. Cancers (Basel) 11: $888,2019$.

83. Kibria G, Ramos EK, Wan Y, Gius DR and Liu H: Exosomes as a drug delivery system in cancer therapy: Potential and challenges. Mol Pharm 15: 3625-3633, 2018.

84. Kobayashi M, Sawada K, Miyamoto M, Shimizu A, Yamamoto M, Kinose Y, Nakamura K, Kawano M, Kodama M, Hashimoto K and Kimura T: Exploring the potential of engineered exosomes as delivery systems for tumor-suppressor microRNA replacement therapy in ovarian cancer. Biochem Biophys Res Commun 527: $153-161,2020$.

85. Nie H, Xie X, Zhang D, Zhou Y, Li B, Li F, Li F, Cheng Y, Mei H, Meng $\mathrm{H}$ and Jia L: Use of lung-specific exosomes for miRNA-126 delivery in non-small cell lung cancer. Nanoscale 12: 877-887, 2020.

86. Qi P, Li Y, Liu X, Jafari FA, Zhang X, Sun Q and Ma Z: Cryptotanshinone suppresses non-Small cell lung cancer via microRNA-146a-5p/EGFR Axis. Int J Biol Sci 15: 1072-1079, 2019.

87. Wang H, Zhang Y,Zhang Y, Liu W and Wang J: Cryptotanshinone inhibits lung cancer invasion via microRNA-133a/matrix metalloproteinase 14 regulation. Oncol Lett 18: 2554-2559, 2019.

88. Hu X, Zhang F, Liu XR, Wu YT and Ni YM: Efficacy and potential MicroRNA mechanism for computed tomography-guided percutaneous radiofrequency ablation of primary lung cancer and lung metastasis from liver cancer. Cell Physiol Biochem 33: 1261-1271, 2014. 
89. Barshack I, Meiri E, Rosenwald S, Lebanony D, Bronfeld M, Aviel-Ronen S, Rosenblatt K, Polak-Charcon S, Leizerman I, Ezagouri M, et al: Differential diagnosis of hepatocellular carcinoma from metastatic tumors in the liver using microRNA expression. Int J Biochem Cell Bio 42: 1355-1362, 2010.

90. Tafsiri E, Darbouy M, Shadmehr MB, Zagryazhskaya A, Alizadeh $\mathbf{J}$ and Karimipoor M: Expression of miRNAs in non-small-cell lung carcinomas and their association with clinicopathological features. Tumour Biol 36: 1603-1612, 2015.

91. Chen Q, Hu H, Jiao D, Yan J, Xu W, Tang X, Chen J and Wang J: MiR-126-3p and miR-451a correlate with clinicopathological features of lung adenocarcinoma: The underlying molecular mechanisms. Oncol Rep 36: 909-917, 2016.

92. Kontarakis Z, Rossi A, Ramas S, Dellinger MT and Stainier DYR: Mir-126 is a conserved modulator of lymphatic development Dev Biol 437: 120-130, 2018

93. Agudo J, Ruzo A, Tung N, Salmon H, Leboeuf M, Hashimoto D Becker C, Garrett-Sinha LA, Baccarini A, Merad M and Brown BD: The miR-126-VEGFR2 axis controls the innate response to pathogen-associated nucleic acids. Nat Immunol 15 : $54-62,2014$
94. Ferretti $\mathrm{C}$ and La Cava A: MiR-126, a new modulator of innate immunity. Cell Mol Immunol 11: 215-217, 2014.

95. Peng J, Yu Z, Xue L, Wang JB, Li J, Liu D, Yang Q and Lin Y: The effect of foxp3-overexpressing Treg cells on non-small cell lung cancer cells. Mol Med Rep 17: 5860-5868, 2018.

96. Qin A, Wen Z, Zhou Y, Li Y, Li Y, Luo J, Ren T and Xu L: MicroRNA-126 regulates the induction and function of CD4(+) Foxp3(+) regulatory T cells through PI3K/AKT pathway. J Cell Mol Med 17: 252-264, 2013

97. Chu F, Hu Y, Zhou Y, Guo M, Lu J, Zheng W, Xu H, Zhao J and Xu L: MicroRNA-126 deficiency enhanced the activation and function of $\mathrm{CD} 4^{+} \mathrm{T}$ cells by elevating IRS-1 pathway. Clin Exp Immunol 191: 166-179, 2018

(i) (9) This work is licensed under a Creative Commons Attribution-NonCommercial-NoDerivatives 4.0 International (CC BY-NC-ND 4.0) License. 